\title{
Intermittent Corticotrophin Treatment: Ventilatory Tests in Asthmatic Subjects
}

\author{
R. C. LOWRY,* M.B., M.R.C.P.; J. S. MACKAY, † B.SC. ; B. SHERIDAN,§ A.I.M.L.T. \\ J. A. WEAVER, $\ddagger$ M.D., M.R.C.P.
}

British Medical Fournal, 1969, 4, 455-456

\begin{abstract}
Cummary : Ventilatory tests (F.E.V. $\cdot_{1}$ /F.V.C.) have been studied in 16 asthmatic subjects during intermittent administration of corticotrophin, and the responses correlated with the plasma cortisol levels. The improvemeat in respiratory function was found to last for a longer period than the enhanced adrenocortical activity.
\end{abstract}

\section{Introduction}

Intermittent treatment regimens with oral steroids (Grant et al., 1965) or corticotrophin (Nelson et al., 1966) have been advocated as a means of avoiding the hypothalamic-pituitary adrenal axis suppression that may occur during long-term treatment with these drugs. This intermittent manner of treatment requires further study to delineate the sustained nature of the therapeutic response which continues in the intervals between each dose-the duration of clinical improvement in diseases such as asthma and rheumatoid arthritis being longer than expected from the known biological effects of these drugs. The present study reports the effect of intermittent corticotrophin treatment on certain respiratory function tests in asthmatic subjects.

\section{Material and Methods}

Sixteen asthmatic patients who had presented with a history of severe intermittent attacks of wheezing and dyspnoea with symptom-free intervals were chosen for study. No serious complicating illness of chest infection was present and the patients were all thought to be sufficiently disabled by the recurring nature of their symptoms to be suitable for long-term treatment with either oral steroids or corticotrophin. Some patients had previously received oral steroids in short courses for status asthmaticus, but an interval of six weeks free from steroid treatment was arbitrarily taken for inclusion of the patient in this study.

F.E.V. ${ }_{1}$ and F.V.C. were measured on a Gaensler-type spirometer (McKerrow et al., 1960) and a mean of two determinations for each of these tests was established. Histamine acid phosphate was then administered in dry micronized form by pressurized aerosol canisters. The dosage, $50 \mu \mathrm{g}$., and method of administration were similar to those described by Oppenheimer et al. (1966). One minute later the first of further duplicate F.E.V..$_{1}$ and F.V.C. estimations was started, and finally these tests were repeated in duplicate five minutes after the histamine spray.

On three initial control days the above experiments were carried out at approximately midday to establish a baseline pattern. On the fourth day, at 7 a.m., the patients were given 40 units of corticotrophin gel (Acthar gel). The respiratory

* Registrar.

t Physician.

\$ Benlar Technician.

Biochemistry Department, Sir George E. Clark Metabolic Unit, Royal Victoria Hospital, Belfast. studies were repeated at midday, and at midday on the following day (fifth day). On the sixth day, at 7 a.m., a further injection of 40 units of corticotrophin gel was given, and respiratory function tests were repeated at midday on days 0 and 7.

At the beginning of the respiratory studies on each day venous blood was taken for estimation of the plasma cortisol (Mattingly, 1962) and also for an eosinophil count.

\section{Results}

Among the 16 patients there was a wide variation in the severity of airway obstruction. The mean F.E.V. $/$ F.V.C. ratio for the 16 patients was $48 \%$ (range 33-68\%), but only two patients had ratios greater than $60 \%$. There was also considerable, but random, variation in the results of the respiratory tests during the three control days-mean deviation from the mean for F.E.V..$_{1}$ at the start of each experiment was 0.08 litre (range $0-0.35$ litre). After treatment with corticotrophin, however, the mean changes in all respiratory function tests were in the expected direction of improvement. The F.E.V. ${ }_{1}$ at zero time for each experiment during the four days of treatment was significantly higher than the mean of the three control days (Table I). It can be seen that the respiratory

TABLE I-Individual F.E.V. (litres) for the 16 Patients at Initial Time (12 Midday) of Each Experiment. Columns 4 and 5 Show Mean
Results for the 3 Control Days in Respect of F.E.V. $._{1} / F . V . C . \%$ (Column 4) and F.E.V.1 (litres) (Column 5)

\begin{tabular}{|c|c|c|c|c|c|c|c|c|}
\hline $\begin{array}{l}\text { Case } \\
\text { No. }\end{array}$ & $\begin{array}{c}\text { Age } \\
\text { (Years) }\end{array}$ & Sex & $\begin{array}{l}\text { F.E.V. } \\
\text { F.V.C. } \%\end{array}$ & Control* & Day 4 & Day 5 & Day 6 & Day 7 \\
\hline $\begin{array}{r}1 \\
2 \\
3 \\
4 \\
5 \\
6 \\
7 \\
8 \\
9 \\
10 \\
11 \\
12 \\
13 \\
14 \\
15 \\
16\end{array}$ & $\begin{array}{l}58 \\
57 \\
29 \\
45 \\
43 \\
46 \\
57 \\
25 \\
47 \\
32 \\
47 \\
72 \\
54 \\
28 \\
63 \\
40\end{array}$ & 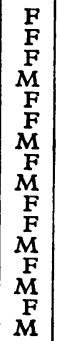 & $\begin{array}{l}59 \\
68 \\
65 \\
50 \\
51 \\
47 \\
34 \\
52 \\
37 \\
33 \\
44 \\
37 \\
53 \\
41 \\
44 \\
55\end{array}$ & $\begin{array}{l}1.23 \\
1.46 \\
2.22 \\
2.0 \\
0.9 \\
0.8 \\
1.1 \\
1.1 \\
1.52 \\
0.79 \\
0.59 \\
0.72 \\
1.07 \\
0.6 \\
1.05 \\
0.85\end{array}$ & $\begin{array}{l}1.45 \\
1.70 \\
2.25 \\
2.05 \\
1.2 \\
1.8 \\
1.45 \\
1.45 \\
1.82 \\
0.7 \\
0.53 \\
0.82 \\
1.15 \\
0.5 \\
1.13 \\
0.95\end{array}$ & $\begin{array}{l}1.57 \\
1.32 \\
2.2 \\
2.2 \\
1.6 \\
2.0 \\
1.75 \\
1.37 \\
1.43 \\
1.0 \\
0.65 \\
0.85 \\
1.3 \\
0.57 \\
1.13 \\
1.1\end{array}$ & $\begin{array}{l}1.4 \\
1.5 \\
2.0 \\
1.97 \\
1.6 \\
1.85 \\
1.6 \\
1.68 \\
2.2 \\
0.77 \\
0.65 \\
0.85 \\
1.1 \\
0.7 \\
1.0 \\
1.28\end{array}$ & $\begin{array}{l}1.63 \\
1.45 \\
2.1 \\
1.92 \\
1.6 \\
1.90 \\
1.75 \\
1.75 \\
1.53 \\
1.05 \\
1.03 \\
0.78 \\
1.6 \\
0.5 \\
0.95 \\
1.30\end{array}$ \\
\hline \multicolumn{4}{|l|}{$\overline{\text { Mean }}$} & $1.13 \pm 0.03$ & $1.31 \pm 0.03$ & $1.38 \pm 0.03$ & $1.39 \pm 0.03$ & $1.43 \pm 0.03$ \\
\hline \multicolumn{3}{|c|}{$\begin{array}{r}\text { Plasma cortisol } \\
(\mu \mathrm{g} .1100 \mathrm{ml} .)\end{array}$} & & & & $8 \cdot 2 \pm$ & & $7 \cdot 2 \pm 0 \cdot 2$ \\
\hline
\end{tabular}

Mean of observations days $1,2,3$

For F.E. . .1, days 4, 5, 6, 7 are significantly different from day $0, P<0.001$. $\begin{aligned} & \text { Difference between control days and day } 4=0.18 ; t=11.69 ; P<0.001 \text {. Differ- } \\ & \text { ence between days } 4 \text { and } 5=0.07 ; t=4.64 ; \mathrm{P}<0.001 \text {. Difference between days } 5\end{aligned}$ ence between days 4 and $5=0.07 ; t=4.64 ; P<0.001$. Difference between days 5
and $6=0.01 ; t=0.68 ; 0.6>P>0.5$. Difference between days 6 and $7=0.04$; and $6=0.01 ; t=0.68 ;$
$t=2.59 ; 0.05>P>0.02$.

improvement after the initial injection of corticotrophin corresponded with a pronounced increment in the plasma cortisol levels from the mean of $10 \mu \mathrm{g} . / 100 \mathrm{ml}$. (for the three control days) to a mean of $37.6 \mu \mathrm{g} . / 100 \mathrm{ml}$. on day 4 . A comparison between days 4 and 5 shows that F.E.V., further improved from 1.31 litres to 1.38 litres, but the plasma cortisol levels had fallen from $37.6 \mu \mathrm{g} . / 100 \mathrm{ml}$. to $8.2 \mu \mathrm{g} . / 100 \mathrm{ml}$. 
There is not so pronounced a tendency to further improvement in F.E.V. ${ }_{1}$ during days 6 and 7 consequent to the second injection of corticotrophin, but comparison between days 6 and 7 shows F.E.V..$_{1}$ of 1.39 and 1.43 litres respectively, with corresponding cortisol levels of $39 \cdot 2$ and $7 \cdot 2 \mu \mathrm{g} . / 100 \mathrm{ml}$.

The pattern of all the respiratory tests after the histamine spray shows similar patterns to the above in terms of the lack of a direct daily relation between respiratory improvement and the cortisol levels (Table II)

TABLE II.-Respiratory Function Tests F.E.V. and F.V.C. (litres) Before and After Histamine Administration

\begin{tabular}{|c|c|c|c|c|c|c|}
\hline & & $\begin{array}{l}\text { Control } \\
\text { Days } \\
\text { (litres) }\end{array}$ & Day 4* & Day $5^{*}$ & $\left|\begin{array}{c}\text { Day 6* } \\
\text { (A.C.T.H.) }\end{array}\right|$ & Day 7* \\
\hline \multirow{2}{*}{$\begin{array}{l}\text { Initial } \\
\text { time } \\
\text { One minute } \\
\text { after } \\
\text { histamine } \\
\text { Five minutes } \\
\text { after }\end{array}$} & $\left\{\begin{array}{l}\text { F.E.V.1 } \\
\text { F.V.C. } \\
\text { F.E.V.1 }\end{array}\right.$ & $\begin{array}{l}1.13 \\
2.35 \\
0.93\end{array}$ & $\begin{array}{l}+0.18 \\
+0.27 \\
+0.17\end{array}$ & $\begin{array}{l}+0.25 \\
+0.26 \\
+0.33\end{array}$ & $\begin{array}{l}+0.26 \\
+0.35 \\
+0.33\end{array}$ & $\begin{array}{l}+0.30 \\
+0.34 \\
+0.30\end{array}$ \\
\hline & $\left\{\begin{array}{l}\text { F.V.C. } \\
\text { F.E.V.1 } \\
\text { F.V.C. }\end{array}\right.$ & $\begin{array}{l}1.91 \\
0.98 \\
2 \cdot 15\end{array}$ & $\begin{array}{l}+0.23 \\
+0.19 \\
+0.27\end{array}$ & $\begin{array}{l}+0.39 \\
+0.26 \\
+0.27\end{array}$ & $\begin{array}{l}+0.43 \\
+0.37 \\
+0.47\end{array}$ & $\begin{array}{l}+0.45 \\
+0.34 \\
+0.38\end{array}$ \\
\hline \multicolumn{2}{|c|}{$\begin{array}{c}\text { Plasma cortisol, } \\
\mu \mathrm{g} . / 100 \mathrm{ml} .\end{array}$} & $10 \cdot 0 \pm 0.18$ & $37.6 \pm 0.83$ & $8 \cdot 2 \pm 0 \cdot 22$ & $39 \cdot 2 \pm 0 \cdot 79$ & $7 \cdot 2 \pm 0 \cdot 2$ \\
\hline
\end{tabular}

* Results of respiratory function tests for the 16 patients on experiment days 4,5 , 6 , and 7 are given as mean improvement in litres over the value of the mean result for the three control days.

\section{Discussion}

In a previous study we investigated the effect of a regimen of intermittent corticotrophin administration on the integrity of the hypothalamo-pituitary adrenal axis (H.P.A.) (Nelson et al., 1966). The findings suggested less suppression of the H.P.A. axis than had been generally reported after treatment with oral steroids. It is uncertain whether this difference was a specific advantage of corticotrophin over oral steroids, as suggested by the work of Savage and his colleagues (Bacon et al., 1968), or whether the intermittent mode of administration had an advantage with regard to H.P.A. suppression similar to some regimens with intermittent oral steroids.

Apart from the question of H.P.A. axis suppression, the interest of these intermittent regimens is how in diseases such as rheumatoid arthritis and asthma they exert a beneficial effect which outlasts their known duration of action. A study of in-vitro lymphocyte transformation to phytohaemagglutinin in blood from rheumatoid subjects during intermittent corticotrophin treatment failed to show any prolonged effect on this lymphocyte activity greater than the duration of the increment in the plasma cortisol level (Nelson et al., 1969).

Though there are several studies (Harter et al., 1963 ; Grant et al., 1965) advocating the use of intermittent regimens of oral steroid treatment, they have been concerned with the effect of such treatment on the possible suppression of hypothalamicpituitary adrenal axis, rather than on investigation of the response of the disease process to such regimens.

The major study of Walsh and Grant (1966) with regard to intermittent use of prednisolone in the treatment of bronchial asthma is of interest in comparison with the present study. They showed that in a group of 245 adult patients $180(74 \%)$ could be maintained by an intermittent prednisolone regimen (20 mg./day on three consecutive days per week). This study also clearly showed that the improvement in F.E.V.1 on the treatment days was maintained on the following four days of placebo treatment. The advantage in the present small study of 16 patients is that by using corticotrophin it is possible to correlate the respiratory function improvements with the fluctuation in plasma cortisol levels and to indicate clearly that for an improvement in respiratory function it is not necessary to maintain a continuous increment of plasma cortisol levels. Owing to the inherent complexities of assessing prednisolone blood levels and possible alterations in cortisol binding and biological half-life of endogenous hydrocortisone during prednisolone therapy, it is not possible to draw clear conclusions from the prednisolone study with regard to the nature of the prolonged response to intermittent therapy.

Deficiencies in this study were the relatively unstable base. line in F.E.V..$_{1}$ during the control three-day period, but this is a usual finding in bronchial asthma. It affects the judgement on how significant was the overall improvement in respiratory function, but the comparison within the treatment days (4 to 7) and correlation of the ventilatory tests with plasma cortisol levels remains valid. It is clear also that the group of patients studied, as judged by F.E.V.1 /F.V.C. ratio, was heterogeneous, and, as well as bronchial asthma patients, contained probably a few subjects suffering mainly from chronic obstructive bronchitis who would be less likely to respond to adrenocortical hormones, thus causing an undue scatter in the results.

Histamine administration has been utilized by Oppenheimer et al. (1968), using more refined respiratory function tests; and in the present study, apart from F.E.V. ${ }_{1}$ /F.V.C. tests being less sensitive, we also found that duplicate responses to histamine inhalation differed widely in the same subject, probably owing to the degree of initial bronchoconstriction and also. because ventilatory tests requiring maximal inspiration and expiration may actually change the airway response to histamine (Simonsson et al., 1967).

Although the response in the ventilatory tests after histamine was variable there was a general deterioration which was not influenced by corticotrophin administration. Thus it was found that respiratory function after histamine declined equally in the control and corticotrophin treatment days, such absolute differences as there were being due solely to the better respiratory function at the beginning of each test on days 4 to 7 . It was not unexpected that the immediate bronchoconstrictor response to histamine inhalation failed to be influenced by corticotrophin administration. An additional feature of this experiment was to repeat the ventilatory tests after a five-minute interval to determine whether recovery from histamine-induced bronchoconstriction was expedited by corticotrophin, but this was also unaffected. For this reason the histamine responses have not been dealt with in more detail.

The regimen utilized in these experiments was corticotrophin gel 40 units at 48-hour intervals; as the plasma cortisol levels show, this qualifies as an intermittent stimulus. We have found in clinical practice in a large group of asthmatic subjects that it is possible to increase the interval to 72-96-hour cycles of treatment, and in some cases even once-weekly injection regimens are possible (Nelson et al., 1966).

We are grateful to Fison's Ltd. for supplying the canisters of histamine acid phosphate.

\section{REFERENCES}

Bacon, P. A., Daly, J. R., Myles, A. B., and Savage, O. (1968). Annals of the Rheumatic Diseases, 27, 7.

Grant, S. D., Forsham, P. H., and DiRaimondo, V. C. (1965). New England Fournal of Medicine, 273, 1115.

Harter, J. G., Reddy, W. J., and Thorn, G. W. (1963). New England Fournal of Medicine, 269, 591.

Mattingly, D. (1962). Fournal of Clinical Pathology, 15, 374.

McKerrow, C. B., McDermott, M., and Gilson, J. C. (1960). Lancet, $1,149$.

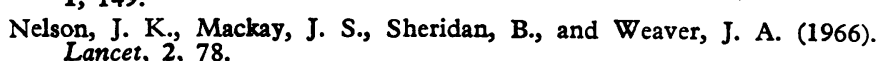

Nelson, S. D., Mackay, J. S., Sheridan, B., and Weaver, J. A. (1969). Annals of the Rheumatic Diseases. In press. Oppenheimer, E. A., Rigatto, M., and Fletcher, C. M. (1968). Lancet,
1, 552 . Simonsson, B. G., Jacobs, F. M., and Nadel, J. A. (1967). American
Review of Respiratory Diseases, 95, 873.

Walsh, S. D., and Grant, I. W. B. (1966). British.Medical fournal, 2, 